\section{Estudo \\ Edobate}

em Cestão

Planejamento
Revista Estudo \& Debate, Lajeado, v. 26, n. 2, 2019. ISSN 1983-036X

DOI: http://dx.doi.org/10.22410/issn.1983-036X.v26i2a2019.1962

\title{
COMPETITIVIDADE DAS EXPORTAÇÓES BRASILEIRAS DE BANANA
}

\author{
José Lucas da Silva Santos ${ }^{1}$, Eliane Pinheiro de Sousa ${ }^{2}$
}

\begin{abstract}
Resumo: Este estudo busca analisar a competitividade das exportaçóes de banana proveniente dos estados do Ceará, Paraná, Rio Grande do Norte, Rio Grande do Sul e Santa Catarina no período de 2003 a 2017 por meio dos indicadores de desempenho. Para atender esse objetivo p, empregaram-se os índices de vantagem comparativa revelada de Balassa (IVCR), vantagem comparativa revelada simétrica (IVCRS) e vantagem comparativa revelada de Vollrath (RCAV). Utilizou-se também o modelo Constant Market Share para identificar as fontes de crescimento das exportações brasileiras de banana, considerando três subperíodos: 2003-2007, 2008-2012 e 2013-2017. Os dados foram extraídos da Secretaria de Comércio Exterior (SECEX), órgão vinculado ao Ministério do Desenvolvimento, Indústria e Comércio Exterior (MDIC). Os resultados mostram que os estados do Rio Grande do Norte e de Santa Catarina registraram vantagem comparativa em relação ao Brasil, enquanto o estado do Paraná apresentou desvantagem comparativa nas exportaçóes de banana durante todo o período considerado, conforme o IVCR, o IVCRS e o RCAV. Com base nesses três índices analisados, verifica-se a presença de vantagem comparativa nas exportaçóes de banana para o estado do Ceará a partir de 2006 e para o estado do Rio Grande do Sul de 2012 a 2015. Ademais, constata-se que o efeito destino das exportaçóes foi o que mais contribuiu nas exportaçóes da commodity analisada quando se compara o segundo subperíodo com o primeiro e o terceiro com o segundo, enquanto que o efeito competitividade foi determinante apenas no terceiro subperíodo quando comparado com o segundo.
\end{abstract}

Palavras-chave: Vantagens comparativas reveladas. Constant Market Share. Banana.

\section{COMPETITIVENESS OF THE BRAZILIAN BANANA EXPORTS}

\begin{abstract}
This study aims to analyze the competitiveness of the exports of banana from the states of Ceará, Paraná, Rio Grande do Norte, Rio Grande do Sul and Santa Catarina in the period from 2003 to 2017 by means of performance indicators. In order to achieve this proposed goal, it was employed Balassa's revealed comparative advantage index (IVCR), symmetrical revealed comparative advantage index (IVCRS) and Vollrath's revealed comparative advantage index (RCAV). It was also used the Constant Market Share model in order to identify the sources of growth of the Brazilian banana exports, taking three subperiods into consideration: 2003-2007, 2008-2012 and 2013-2017. The data were extracted from the Foreign Trade Secretariat (Secex), an authority
\end{abstract}

1 Economista pela Universidade Regional do Cariri (URCA).

2 Pós-Doutora em Economia Aplicada pela Escola Superior de Agricultura Luiz de Queiroz da Universidade de São Paulo (USP) e Professora Associada do Departamento de Economia da Universidade Regional do Cariri (URCA). 
linked to the Ministry of Development, Industry and Foreign Trade (MDIC). The results show that the states of Rio Grande do Norte and Santa Catarina exhibited comparative advantage in relation to Brazil, whereas the state of Paraná exhibited comparative disadvantage in the exports of banana during the entire period under analysis, according to the IVCR, the IVCRS and the RCAV. Based on these three indices under analysis, one may observe the presence of comparative advantage in the exports of banana for the state of Ceará from 2006 and for the state of Rio Grande do Sul from 2012 to 2015. In addition, the effect of exports was the one that contributed the most to exports of the commodity analyzed when comparing the second subperiod with the first and third with the second, while the competitiveness effect was decisive only in the third subperiod when compared with the second.

Keywords: Revealed comparative advantages. Constant Market Share. Banana.

\section{INTRODUÇÁO}

A fruticultura é um dos principais setores de destaque do agronegócio brasileiro, conquistando resultados expressivos e gerando oportunidades para o País. O Brasil destacase como o terceiro maior produtor de frutas no mercado internacional, ficando atrás apenas da China e da Índia e vem mostrando a sua grande variedade de culturas produzidas em todo seu território e em diversos climas (SEBRAE, 2015). Dados do Ministério do Desenvolvimento, Indústria e Comércio Exterior (MDIC, 2018) mostram que as vendas externas de frutas frescas no País atingiram US\$714,8 milhóes em 2017. Em 2003, as exportaçóes de frutas frescas, em valores de dezembro de 2017, eram aproximadamente US\$ 595,8 milhóes. No tocante ao volume exportado, passaram de 684,4 mil toneladas em 2003, para 807,4 mil toneladas em 2017.

Dentre as frutas frescas vendidas no mercado internacional, a banana tem mostrado a sua potencialidade no sentido de ser uma cultura capaz de produzir em grande escala devido o Brasil apresentar clima favorável, grande extensão de terras cultiváveis e recursos hídricos. Associados a esses fatores, Pimentel (2006) destaca que a produção de banana se torna atrativa em virtude do elevado rendimento por hectare, ciclo curto dos bananais, facilidade de propagaçáo da bananeira e do manejo da fruta, rápida maturaçấo e armazenamento, e conscientização do seu valor nutritivo pelo consumidor.

Por esse ângulo, esta commodity tem mostrado a sua relevância na pauta de exportaçóes de frutas frescas brasileira, proporcionando, em 2017, um montante de US\$ 11,6 milhóes (MDIC, 2018). Ao analisar os últimos três anos, constatou-se que, em média, 99,4\% das exportações desta fruta foram provenientes dos estados do Ceará, Paraná, Rio Grande do Norte, Rio Grande do Sul e Santa Catarina, sendo que este último foi responsável por $80 \%$ das exportaçóes brasileiras de banana em 2017. Quanto ao destino de suas exportaçóes, em torno de $88 \%$ foram enviadas, em 2017, para dois países membros do MERCOSUL (Uruguai, com valor de US\$ 6,34 milhóes, e Argentina, com US\$ 3,91 milhóes), enquanto que, em média, $11 \%$ foram destinadas para três países da União Europeia (Polônia, com valor de US\$ 668,6 mil, Holanda com US\$ 408,7 mil e Reino Unido com US\$228,1 mil).

De acordo com dados do Ministério do Desenvolvimento, Indústria e Comércio Exterior (MDIC, 2018), a banana liderou a oitava posição como a fruta com maior valor exportado em 2017, sendo responsável por 1,63\% do valor exportado de frutas no Brasil. Em relação ao volume exportado, este produto ocupou a sétima posiçáa no ranking com 
uma participação de 5,13\% em 2017. Embora essa commodity tenha se destacado dentre as frutas em termos de valor e volume exportado, tais participaçóes relativas são modestas.

Apesar das participaçóes relativas do valor e volume exportado de banana não serem expressivas, esta fruta mostra-se relevante no contexto social e econômico, proporcionando fonte de renda para muitas famílias que vivem no campo, além de ser um alimento complementar na dieta da população (FIORAVANÇO, 2003). Neste sentido, a comercialização desta commodity brasileira para o mercado externo proporciona divisas para o País, favorecendo o saldo positivo na balança comercial, e, ao mesmo tempo, incentiva os produtores a expandirem a bananicultura.

Para a banana ganhar espaço e competitividade no mercado internacional, e, mais especificamente, nos Estados Unidos e na União Europeia, o Brasil vem adotando melhorias tecnológicas na produção e comercialização, preparando-se para adaptar seu produto às exigências e aos padróes internacionais (SEBRAE, 2008). Contudo, de 2016 a 2017, as exportações desta fruta caíram significativamente, ou seja, 44,69\% (MDIC, 2018). Isso reflete a baixa qualidade da fruta para atender às exigências dos principais centros consumidores internacionalmente, bem como a menor competitividade gerada frente aos grandes players mundiais na exploração (CEPEA, 2017).

Segundo Goulart Júnior (2017), a queda das exportaçóes de banana provenientes do estado de Santa Catarina pode ser atribuída aos problemas fitossanitários e climáticos que comprometeram a qualidade da fruta. Esses fatores reduziram a oferta relativa no mercado, mantendo os preços acima da média. Quanto ao Ceará e ao Rio Grande do Norte, a diminuição das exportaçóes de banana pode estar associada à redução da demanda europeia, visto que esses dois estados nordestinos dominam as exportaçóes nacionais para a União Europeia. Vale destacar também que, conforme Vitti (2009), as oscilaçóes de preço e, consequentemente, do volume de exportação são afetadas pela variação do dólar, que, por sua vez, influencia diretamente o período de adubação, interferindo a qualidade da banana, e pela exigência de certificação para a União Europeia, assim como o tipo de banana exportado, que, segundo Oranje (2003), a nanica é uma das variedades mais enviada do Brasil ao mercado internacional.

Em face do exposto, questiona-se sobre o comportamento das exportaçóes brasileiras de banana, realizando uma análise comparativa das exportaçóes de banana provenientes dos principais estados que comercializam esta fruta com o mercado internacional, por meio de indicadores de desempenho, como os índices de Vantagem Comparativa Revelada $\left(I V C R_{i}\right)$, Vantagem Comparativa Revela Simétrica $\left(I V C R S_{i j}\right)$ e Vantagem Comparativa Revelada de Vollrath $\left(R C A V_{i}\right)$. Ademais, para identificar as fontes de crescimento das exportaçóes brasileiras de banana, adotou-se o modelo Constant Market Share (CMS).

Nesse cenário, estudos desta natureza mostram-se relevantes no sentido de colaborar para a elaboração de políticas que fortaleçam o País a conquistar novos mercados, de tal forma que possa aumentar a sua competitividade no âmbito internacional. Com isso, esse tema tem sido discutido na literatura, seja no âmbito brasileiro de frutas, dentre elas, a banana (ORANJE, 2003; CARVALHO; CUNHA FILHO, 2007; VITTI, 2009), considerando especialmente as exportaçóes brasileiras de bananas (SOUSA NETO; MOURA; CABRAL, 2006), as exportaçôes de bananas provenientes do Ceará (SOARES; SOUSA; BARBOSA, 
2013), do Rio Grande do Norte (ANDRADE; COSTA; MAIA, 2008), assim como para outras frutas, como abordados nos estudos recentes desenvolvidos por Santos e Sousa (2017) para o melão; e Silva, Ferreira e Lima (2016) para manga e uva.

A escolha da banana deu-se em virtude de os trabalhos nesta linha de pesquisa náo analisarem especificamente as exportaçóes brasileiras de banana de forma desagregada por estado por meio de indicadores de desempenho. Os estudos realizados que abordam esse setor tratam em conjunto com outros produtos, como são os casos, por exemplo, dos trabalhos de Oranje (2003), Carvalho e Cunha Filho (2007), e Vitti (2009) que verificaram a competitividade da fruticultura brasileira no mercado internacional; e Soares, Sousa e Barbosa (2013) que analisaram o desempenho exportador do agronegócio no estado do Ceará. Além disso, é importante analisar as fontes de crescimento das exportaçôes brasileiras de banana, realizando-se por meio do modelo CMS, sendo que, dentre tais estudos citados, apenas Sousa Neto, Moura e Cabral (2006) e Vitti (2009) utilizaram esse método analítico.

Desta forma, este estudo se propóe analisar a competitividade das exportaçóes de banana proveniente dos estados do Ceará, Paraná, Rio Grande do Norte, Rio Grande do Sul e Santa Catarina no período de 2003 a 2017 por meio dos indicadores de competitividade, bem como identificar as fontes de crescimento das exportaçóes brasileiras de banana, considerando três subperíodos: 2003-2007, 2008-2012 e 2013-2017.

$\mathrm{O}$ artigo está estruturado em cinco seçôes, além desta introdução. Na segunda seção, é apresentado o referencial teórico, com o objetivo de discutir as teorias do comércio internacional; na terceira, são mostrados os estudos empíricos sobre a competitividade das exportaçóes brasileiras de banana; na quarta, é apresentada a metodologia empregada nesta pesquisa; na quinta, são mostrados e discutidos os resultados; e a última seção, é reservada às considerações finais deste estudo.

\section{REFERENCIAL TEÓRICO}

O processo de intensificação das transaçôes comerciais no âmbito internacional fez surgir a partir do século XVIII estudos que tentassem explicar esse efeito globalizante, como as teorias dos economistas clássicos Adam Smith e David Ricardo, que formularam, respectivamente, as teorias das vantagens absolutas e das vantagens comparativas. De início, ambas as teorias consideram o fator trabalho como único para determinar os custos de produção (CARMO; MARIANO, 2010; OLIVEIRA; ROSA, 2013).

Neste sentido, a Teoria das Vantagens Absolutas destaca que cada país deve se especializar na produçáo de bens que seja mais eficiente. Para tanto, uma das condiçóes necessárias para o estabelecimento do comércio entre duas naçóes seria a demanda de algum produto cuja produção houvesse uma vantagem absoluta, isto é, essa nação deveria ter necessariamente condiçóes de produçáo mais favorável que as do país para a qual pretende exportar (CARMO; MARIANO, 2010). Contudo, tal teoria não consegue explicar a existência de comércio internacional quando um país é mais eficiente na produção de todos os bens. Nessa situação, a explicação foi dada por David Ricardo.

A Teoria das Vantagens Comparativas, criada por Ricardo, defende que as trocas comerciais entre os países promoveriam vantagens, mesmo para uma situação na qual um 
país tivesse vantagens absolutas em todos os bens considerados, quando comparado com outros países (RICARDO, 1996). Em outros temos, a teoria previa que cada país deveria se especializar na produção de bens que fosse relativamente (comparativamente) mais eficiente, devendo-se fazer uma análise comparativa entre os custos de produção do bem nas duas naçóes que estiver sendo consideradas. Desta forma, com base nessa hipótese, a especialização promoveria o aumento da capacidade produtiva, o que, por sua vez, proporciona aumento da produção (CARMO; MARIANO, 2010).

Nesse contexto, surgiu em conformidade com a teoria de David Ricardo a Teoria das Vantagens Comparativas Reveladas de Balassa, em 1965, que tem por objetivo analisar e identificar as commodities de um determinado país que possui vantagem comparativa em termos de produção e exportação. Para isso, fundamenta-se a partir de dados revelados, ou seja, para analisar a competitividade de um dado bem, é necessário que tenha sido comercializado em um determinado período de tempo (BALASSA, 1965).

Após as teorias clássicas, surgiu o Teorema Neoclássico de Hecksher-Ohlin (HO), que prevê que cada país se especializará na produção de bens intensivos no fator de produção relativamente abundante em seu território, ou seja, que as vantagens comparativas são determinadas em razão das diferenças nas dotaçóes de fatores de produção. Com base nessa teoria do comércio internacional, a proporção dos fatores de produção de cada país determinará o seu padrão de importação e exportação, sendo que entre duas naçóes deve-se observar o fato de que os países tendem a exportar mercadorias provenientes de seus fatores de produção abundante, enquanto que importa bens cujos fatores sejam mais escassos (CASSANO, 2002). Com isso, pode-se afirmar que a oferta relativa de fatores de produçáo e a sua intensidade do emprego na fabricação de uma dada mercadoria são responsáveis pela determinação dos padrôes de especialização.

Em 1948, Paul Samuelson, com base em pressupostos não muito realistas, utilizou de métodos matemáticos com o objetivo de testar a hipótese de equalização dos preços relativos dos fatores de produção. Diante disso, formou-se o modelo Heckscher-Ohlin-Samuelson (H-O-S) (OLIVEIRA, 2007). Esse teorema afirma que o livre comércio promoverá uma equalizaçáo dos preços dos fatores de produção, ocasionando o aumento da remuneraçáo do fator abundante e redução da remuneração do fator escasso (CARDOSO, 2003). Vale destacar que esse teorema somente será válido caso a tecnologia seja constante.

Segundo Coronel, Sousa e Amorim (2011), os pressupostos formulados por H-O tiveram grande importância e influência na formulação de novas teorias ou modelos que tentassem explicar o comércio entre naçóes dentro do contexto de intensificação do processo de globalização, como o modelo Linder. Este modelo afirma que o fluxo comercial será mais intensivo entre os países com estruturas de demanda semelhantes, é dizer, quanto mais parecidos forem os gostos dos consumidores, maior será o fluxo comercial entre eles. Tal modelo afirma ainda que o comércio internacional se dá, preferencialmente, entre os países que possuem o mesmo estágio de desenvolvimento, medido pela renda per capita (ANDREKOWISK, 2010).

Ademais, vale ressaltar que as transformaçóes econômicas nas décadas de 1980 e 1990 não ocorreram exclusivamente pela dotação dos fatores do país, mas também por outras variáveis que afetam a competitividade do comércio mundial, como taxa de câmbio, 
custos, produtividade, fatores sistêmicos, dentre outros (CORONEL; SOUSA; AMORIM, 2011).

\section{REVISÁO DE LITERATURA}

A competitividade das exportaçóes brasileiras de frutas, dentre elas, a banana, foi objeto de estudo de Oranje (2003), Carvalho e Cunha Filho (2007), e Vitti (2009). No caso do trabalho realizado por Oranje (2003), as frutas consideradas foram: banana, laranja, mamão, maçã, manga, melão e uva. Para avaliar a competitividade das exportaçóes brasileiras dessas frutas nas décadas de 1980 e 1990, empregou os indicadores de vantagem comparativa revelada $\left(I V C R_{i}\right)$ e de elasticidade de substituição, que foi estimada por meio do Sistema de Regressóes Aparentemente Não-Relacionadas (SUR). Os resultados da vantagem comparativa revelada no comércio de banana mostraram valores positivos elevados no Equador, Costa Rica e Panamá nas décadas de 1980 e 1990, enquanto, no Brasil, o IVCR oscilou com valor entre 0 e 1 , logo a banana apresentou desvantagem comparativa. Esse resultado para as exportaçóes brasileiras de banana também foi encontrado por Carvalho e Cunha Filho (2007) para o período de 1990 a 2003. Além da banana, esses autores analisaram a competitividade das exportaçóes brasileiras de castanha de caju, manga, melão, laranja, maçã, e uva, mediante os indicadores de vantagem comparativa revelada, taxa de cobertura e de desempenho.

Vitti (2009) analisou a competitividade das exportações brasileiras de frutas, considerando a banana, lima / limão, maçã, mamão, manga, melão e uva, e buscou identificar os fatores que contribuíram para o aumento das exportaçóes brasileiras dessas frutas entre os anos de 1989 a 2006. Para tal, utilizou o indicador de vantagem comparativa revelada $\left(I V C R_{i}\right)$ e o modelo Constant Market Share (CMS). Dentre tais frutas avaliadas, a banana foi a única que apresentou $I V C R_{i}$ inferiores à unidade em todo o período estudado. Quanto aos efeitos que mais contribuíram para o desempenho das exportaçóes de frutas brasileiras, o efeito competitividade foi o mais relevante, especialmente no segundo período analisado. Aplicando o modelo CMS, Sousa Neto, Moura e Cabral (2006) também verificaram que o efeito competitividade foi preponderante para explicar o aumento das exportaçóes brasileiras de banana no período de 1996 a 2003.

Andrade, Costa e Maia (2008) buscaram verificar a competitividade das exportaçóes de banana, mamão, manga, melão e melancia do Rio Grande do Norte em relação ao Brasil durante o período de 1999 a 2005. Para cumprir esse objetivo, utilizaram os indicadores de vantagem comparativa revelada $(I V C R)$, market-share e contribuição ao saldo (CS). Com base no $I V C R_{i}$, constataram que, em 1999, o Rio Grande do Norte registrou desvantagem comparativa em relação ao Brasil nas exportaçóes de banana, mas, a partir de 2000, esse estado passou a apresentar vantagem comparativa na exportação dessa fruta em relação ao Brasil. Os resultados mostraram ainda market-share crescente e saldos comerciais positivos para a banana durante o período analisado.

Por sua vez, Soares, Sousa e Barbosa (2013) analisaram a competitividade das exportaçóes de castanha de caju, mel de abelha, ceras vegetais, abacaxi, banana, melão, melancia, couros e peles, lagosta, camarão, flores e extrato vegetal do Ceará em relação ao Brasil durante o período de 2001 a 2011. Esses autores empregaram os indicadores 
de vantagem comparativa revelada de Vollrath $(R C A V)$, contribuição ao saldo comercial (CSC), competitividade revelada $(\mathrm{CR})$ e comércio intraindústria $(\mathrm{G}-\mathrm{L})$. No tocante à banana, os resultados sinalizaram vantagem comparativa revelada de Vollrath a partir de 2006 e comércio interindústria.

No Quadro 1, faz-se uma síntese dos estudos sobre competitividade das exportaçóes brasileiras de frutas, dentre elas, a banana, utilizando indicadores de comércio internacional.

Quadro 1 - Síntese dos estudos empíricos

\begin{tabular}{|c|c|c|c|c|c|}
\hline Autores & País/Estado & Período & Produtos & Métodos & Resultados \\
\hline Oranje (2003) & $\begin{array}{c}\text { Brasil, Equador, } \\
\text { Costa Rica, } \\
\text { Colômbia, } \\
\text { Filipinas e } \\
\text { Panamá } \\
\end{array}$ & $\begin{array}{c}\text { Décadas } \\
\text { de } 1980 \text { e } \\
1990\end{array}$ & $\begin{array}{c}\text { Banana, laranja, } \\
\text { mamão, maçâ, manga, } \\
\text { melăo e uva }\end{array}$ & $\begin{array}{c}\operatorname{IVCR}_{\mathrm{i}} \mathrm{e} \\
\text { elasticidade de } \\
\text { substituiçấo }\end{array}$ & $\begin{array}{c}0<\mathrm{IVCR}_{\mathrm{i}} \leq 1 \text { para } \\
\text { a banana no } \\
\text { Brasil }\end{array}$ \\
\hline $\begin{array}{c}\text { Sousa Neto, } \\
\text { Moura e } \\
\text { Cabral }(2006) \\
\end{array}$ & Brasil & $\begin{array}{l}1996 \mathrm{a} \\
2003\end{array}$ & Banana & CMS & $\begin{array}{c}\text { Efeito } \\
\text { competitividade }\end{array}$ \\
\hline $\begin{array}{l}\text { Carvalho e } \\
\text { Cunha Filho } \\
(2007)\end{array}$ & Brasil & $\begin{array}{c}1990 \mathrm{a} \\
2003\end{array}$ & $\begin{array}{l}\text { Castanha de caju, } \\
\text { manga, meláo, laranja, } \\
\text { maçã, banana e uva }\end{array}$ & $\begin{array}{l}\text { IVCR, }_{\mathrm{i}} \text {, taxa } \\
\text { de cobertura e } \\
\text { indicador de } \\
\text { desempenho } \\
\end{array}$ & $\begin{array}{c}0<\mathrm{IVCR}_{\mathrm{i}} \leq 1 \text { para } \\
\text { a banana }\end{array}$ \\
\hline $\begin{array}{l}\text { Andrade, } \\
\text { Costa e Maia } \\
(2008)\end{array}$ & $\begin{array}{c}\text { Rio Grande do } \\
\text { Norte }\end{array}$ & $\begin{array}{l}1999 \mathrm{a} \\
2005\end{array}$ & $\begin{array}{l}\text { Banana, mamão, } \\
\text { manga, melão e } \\
\text { melancia }\end{array}$ & $\begin{array}{l}\text { IVCR, }_{i} \text { market- } \\
\text { share e CS }\end{array}$ & $\begin{array}{c}0<\mathrm{IVCR}_{\mathrm{i}} \leq 1 \text { para } \\
\text { a banana em } \\
1999 \text { e IVCR }>1 \\
\text { a partir de } 2000\end{array}$ \\
\hline Vitti (2009) & Brasil & $\begin{array}{c}1989 a \\
2006\end{array}$ & $\begin{array}{l}\text { Banana, lima/limão, } \\
\text { maçá, mamão, manga, } \\
\text { meláo e uva }\end{array}$ & $\mathrm{IVCR}_{\mathrm{i}}$ e CMS & $\begin{array}{c}0<\text { IVCR }_{\mathrm{i}} \leq 1 \text { para } \\
\text { a banana } \\
\text { Efeito } \\
\text { competitividade }\end{array}$ \\
\hline $\begin{array}{l}\text { Soares, Sousa } \\
\text { e Barbosa } \\
(2013)\end{array}$ & Ceará & $\begin{array}{c}2001 \mathrm{a} \\
2011\end{array}$ & $\begin{array}{c}\text { Castanha de caju, mel } \\
\text { de abelha, ceras vegetais, } \\
\text { abacaxi, banana, melão, } \\
\text { melancia, couros e } \\
\text { peles, lagosta, camarão, } \\
\text { flores e extrato vegetal }\end{array}$ & $\begin{array}{c}\text { RCAV, CSC, } \\
\text { CR e G-L }\end{array}$ & $\begin{array}{c}\text { RCAV }>1 \text { para a } \\
\text { banana a partir } \\
\text { de } 2006\end{array}$ \\
\hline
\end{tabular}

Fonte: organização dos autores.

Dentre esses estudos citados, apenas Andrade, Costa e Maia (2008) e Soares, Sousa e Barbosa (2013) avaliaram a competitividade das exportaçóes de banana, considerando, respectivamente, o Rio Grande do Norte e o Ceará em relação ao Brasil. Além da análise desagregada desses dois estados, este estudo incorpora também os três estados sulistas (Paraná, Rio Grande do Sul e Santa Catarina) e abrange um período mais recente (2003 a 2017). Vale destacar ainda a contribuição metodológica deste trabalho em relação aos estudos mencionados, visto que somente o artigo de Soares, Sousa e Barbosa (2013) utilizou o indicador de vantagem comparativa revelada de Vollrath e nenhum desses empregou o indicador de vantagem comparativa revelada simétrica para a banana. 


\section{METODOLOGIA}

\subsection{Fonte de Dados}

Os dados empregados nesta pesquisa consistem em dados de exportaçóes de banana, Free on Board (FOB) em dólares, dos estados do Ceará, Paraná, Rio Grande do Norte, Rio Grande do Sul e Santa Catarina, obtidos junto ao Sistema de Análise das Informaçóes de Comércio Exterior (ALICE) da Secretaria de Comércio Exterior (SECEX) (MDIC, 2018) no período de 2003 a 2017. Com base nos dados do MDIC (2018), 99,51\% do valor exportado de banana, em 2017, concentraram-se nesses Estados supracitados. Ademais, cabe destacar que a análise das exportaçóes de banana foi realizada com base no código SH4 08.03 da Tabela da Nomenclatura Comum do Mercosul.

Utilizaram-se também dados, em dólares, de exportações e importaçóes mundiais, dos países do Mercosul (Argentina e Uruguai) e dos países da União Europeia (Polônia e Holanda), adotados pela United Nations Commodity Trade Statistics Databases (Un Comtrade) (WORLD INTEGRATED TRADE SOLUCION, 2018), para o período de 2003 a 2017.

Carvalho (1995) sugere que a análise pelo modelo CMS seja desagregada em períodos mais curtos como forma de possibilitar maior segurança na verificação das modificações mais frequentes ocorridas entre um dado período considerado. A delimitação desses subperíodos deve considerar fatos econômicos marcantes que possam impactar nas exportaçóes do produto em análise. Seguindo essa recomendação, o período selecionado (2003 a 2017) foi desagregado em três subperíodos: primeiro subperíodo (2003-2007), que representa o período que antecedeu a crise financeira internacional de 2008; segundo subperíodo (20082012), que indica a etapa pós-crise, e que também antecedeu a queda das exportações de banana brasileira; e terceiro subperíodo (2013-2017), que corresponde a fase mais recente das exportações de banana, após o início da queda das exportações em 2014.

Para avaliar a competitividade das exportaçóes de banana provenientes dos principais estados brasileiros exportadores desta commodity no período de 2003 a 2017, utilizaramse os indicadores de Vantagem Comparativa Revelada $\left(I V C R_{i}\right)$, Vantagem Comparativa Revelada Simétrica $\left(I V C R S_{i j}\right)$ e Vantagem Comparativa Revelada de Vollrath $\left(R C A V_{i}\right)$. Além disso, para identificar as fontes de crescimento das exportaçóes brasileiras de banana, considerando três subperíodos (2003-2007, 2008-2012 e 2013-2017), empregou-se o modelo Constant Market Share (CMS).

\section{2 Índice de Vantagem Comparativa Revelada}

O Índice de Vantagem Comparativa Revelada (IVCR $)$, proposto por Balassa (1965), baseia-se na teoria clássica das vantagens comparativas criada por David Ricardo, sendo uma medida de comparação para dados de exportaçóes de uma dada região. Em outras palavras, tal indicador mede a participação de um determinado produto no total das exportaçóes de um estado em relação à parcela das exportações do país do mesmo produto no total. Vale ressaltar que o IVCR constitui-se uma medida revelada, pois seu cálculo está baseado em 
dados observados, ex post ao comércio (SIQUEIRA; PINHA, 2011). O cálculo deste índice é representado pela equação (1):

$$
I V C R_{i}=\frac{\frac{X_{i j}}{X_{j}}}{\frac{X_{i z}}{X_{z}}}
$$

Em que: $i$ representa o produto analisado (banana), $j$ se refere aos estados considerados (Ceará, Paraná, Rio Grande do Norte, Rio Grande do Sul e Santa Catarina) e z indica o país em análise (Brasil); Xij diz respeito ao valor das exportaçóes de $i$ em cada estado considerado; $X i z$ corresponde ao valor das exportaçóes brasileiras do produto $i ; X j$ é o valor total das exportaçóes de cada estado; e $X z$ é o valor total das exportaçóes do país.

Neste estudo, adotou-se a classificação do IVCR estabelecida por Hinloopen e Marrewijk (2001) e aplicados por Santos, Sousa e Soares (2017) para a competitividade do agronegócio do Nordeste brasileiro, cujas classes encontram-se descritas no Quadro 2.

Quadro 2 - Classificação do Índice de Vantagem Comparativa Revelada $(I V C R)$

\begin{tabular}{|c|c|}
\hline Classes & Classificação \\
\hline $0<I V C R_{i} \leq 1$ & O produto náo possui vantagem comparativa revelada \\
\hline $1<I V C R_{i} \leq 2$ & O produto possui fraca vantagem comparativa revelada \\
\hline $2<I V C R_{i} \leq 4$ & O produto possui média vantagem comparativa revelada \\
\hline$I V C R_{i}>4$ & O produto possui forte vantagem comparativa revelada \\
\hline
\end{tabular}

Fonte: elaborado pelos autores com base em Hinloopen e Marrewijk (2001).

De acordo com Lazaretti et al. (2017), o IVCR é utilizado significativamente na literatura especializada, servindo para delinear os padróes de comércio de uma dada economia. Apesar de ser amplamente empregado, conforme Kim (2015), esse índice tem recebido críticas associadas à falta de um fundamento teórico e aplicabilidade empírica. Para Oliveira e Schlindwein (2015, p. 114), "esse índice apresenta uma limitação, o fato de ser assimétrico para os valores superiores a unidade”. Desta forma, com o intuito de superar essas deficiências, a literatura tem utilizado versóes alternativas, como os Índices de Vantagem Comparativa Revelada Simétrica e Vantagem Comparativa Revelada de Vollrath.

\section{3 Índice de Vantagem Comparativa Revelada Simétrica}

Segundo Laursen (2015), o Índice de Vantagem Comparativa Revelada (IVCR) deve ser ajustado de modo a ficar simétrico em torno do seu valor neutro. $O$ índice ajustado proposto é denominado de Índice de Vantagem Comparativa Revelada Simétrica $\left(I V C R S_{i j}\right)$, podendo ser expresso pela equação (2):

$$
I V C R S_{i j}=\frac{I V C R_{i}-1}{I V C R_{i}+1}
$$


Esse índice varia entre -1 e 1 e classifica-se conforme mostrado no Quadro 3. Estudos como de Oliveira e Schlindwein (2015) e Santos, Sousa e Soares (2017) adotaram esse índice, respectivamente, para o complexo da soja na regiáo Centro-Oeste e para os principais produtos do agronegócio na região Nordeste brasileira.

Quadro 3 - Classificação do Índice de Vantagem Comparativa Revelada Simétrica $\left(I V C R S_{i j}\right)$

\begin{tabular}{|c|c|}
\hline Classes & Classificação \\
\hline$-1<I V C R S_{i j}<0$ & Não possui vantagem comparativa revelada na exportação do produto \\
\hline $0<I V C R S_{i j}<1$ & Possui vantagem comparativa revelada na exportaçáo do produto \\
\hline
\end{tabular}

Fonte: elaborado pelos autores com base em Laursen (2015).

A discussão teórica destaca as propriedades do $I V C R S_{i j}$ e evidências empíricas, com base no teste de Jarque-Bera para normalidade dos termos de erro de regressão (LAURSEN, 2015).

\section{4 Índice de Vantagem Comparativa Revelada de Vollrath}

Conforme Bender e Li (2002), o Índice de Vantagem Comparativa Revelada, proposto por Balassa em 1965, apresenta uma limitação metodológica, gerando dupla contagem do setor no total do país, bem como do país no total do mundo. Para evitar essa limitação, tais autores sugerem o uso do Índice de Vantagem Comparativa Revelada de Vollrath $\left(R C A V_{i}\right)$, podendo ser expresso pela equação (3):

$$
R C A V_{i}=\frac{\frac{X_{i j}}{\left(\sum_{i} X_{i j}\right)-X_{i j}}}{\left[\left(\sum_{j} X_{i j}\right)-X_{i j}\right.}
$$

Em que: $i$ indica o produto avaliado (banana); $j$ refere-se aos estados analisados (CE, PR, RN, RS e SC); $X_{i j} X_{i j}$ diz respeito ao valor das exportaçóes de banana desses estados considerados; $\sum_{i} X_{i j}$ corresponde ao valor total das exportações desses estados considerados; $\sum_{j} X_{i j}$ corresponde ao valor total das exportaçóes brasileiras de banana; $\sum_{j} \sum_{i} X_{i j}$ refere-se ao valor total das exportaçóes brasileiras.

O Quadro 4 apresenta as classes do $R C A V_{i}$, seguindo a classificação proposta por Bender e Li (2002) e empregado em estudos desenvolvidos por Barbosa et al. (2011) para 
o setor de carnes; Silva; Ferreira e Lima (2016) para manga e uva; e Santos e Santos (2016) para melão.

Quadro 4 - Classificação do Índice de Vantagem Comparativa Revelada de Vollrath $(R C A V)$

\begin{tabular}{|c|c|}
\hline Classes & Classificação \\
\hline$R C A V_{i}>1$ & Apresenta vantagem comparativa revelada na exportação do produto \\
\hline$R C A V_{i}<1$ & Possui desvantagem comparativa revelada na exportação do produto \\
\hline
\end{tabular}

Fonte: elaborado pelos autores com base em Bender e Li (2002).

Tal indicador tem sido largamente utilizado na literatura atual, haja vista que mostra avanços metodológicos em relação ao Índice de Vantagem Comparativa Revelada formulada por Balassa (SANTOS; SANTOS, 2016).

\subsection{Modelo Constant Market Share}

O modelo Constant Market Share (CMS) é uma técnica capaz de analisar padróes e tendências de comercialização e, consequentemente, conseguir subsídios para a formulação de políticas (SANTOS; SOUSA, 2017). Tal modelo baseia-se em uma identidade que equipara a variação no valor das exportações à soma das variações decorrentes do crescimento do comércio mundial, do padrão setorial da pauta de exportações, da orientação geográfica das vendas externas e da competitividade (LIMA; LÉLIS; CUNHA, 2015). Isto é, o modelo atribui o crescimento favorável ou desfavorável do setor exportador de um determinado país ao crescimento do comércio internacional, à estrutura das exportaçóes, ao mercado de destino e à competitividade (MENDONÇA et al. 2009).

Para Silva, Ferreira e Lima (2016), o modelo CMS tem como objetivo analisar a participação de uma determinada região que mantém fluxo comercial com o mercado mundial, a partir da análise desagregada das principais tendências de crescimento das exportações ou importações, mediante seus principais determinantes. Além disso, segundo Silva e Martins (2012), o CMS apoia-se na premissa básica de que a participação das exportaçóes de um determinado país tende a permanecer constante entre dois períodos de tempo e que as mudanças ocorridas aplicam-se pelos efeitos do crescimento mundial, da composição do produto analisado e por sua competitividade no mercado internacional.

Algebricamente, conforme Carvalho (2004), os efeitos do comércio podem ser representados pela equação (4):

$$
\sum_{j}\left(V_{j}^{\prime}-V_{j}\right)=\left(r V_{j}\right)+\sum_{j}\left(r_{j}-r\right) V_{j}+\sum\left(V_{j}^{\prime}-V_{j}-r_{j} V_{j}\right)
$$

Em que: $\sum_{j=1}^{n} \boldsymbol{V}_{j}^{\prime}-\sum_{j=1}^{n} \boldsymbol{V}_{j}-\sum_{j=1}^{n} \boldsymbol{r}_{j} \boldsymbol{V}_{j}$ refere-se ao efeito crescimento do comércio mundial de banana; $\sum_{j=1}^{n} \boldsymbol{r}_{j} \boldsymbol{V}_{j}-\sum_{j=1}^{n} \boldsymbol{r} \boldsymbol{V}_{j}$, efeito destino das exportaçóes; e $\sum_{j=1}^{n} \boldsymbol{V}_{j}^{\prime}-\sum_{j=1}^{n} \boldsymbol{V}_{j}-\sum_{j=1}^{n} \boldsymbol{r}_{j} \boldsymbol{V}_{j}$, efeito competitividade; $V^{\prime}{ }_{j}-V_{j}$ corresponde ao crescimento efetivo do valor das exportaçóes de banana do país analisado para o mercado 
$j$, sendo que $V_{j}$ e $V^{\prime}{ }_{j}$ referem-se ao valor das exportações de banana do país considerado para o mercado $j$, nos períodos 1 e 2 , respectivamente; e $r j$ e $r$ diz respeito, respectivamente, às taxas de crescimento percentual do valor das exportaçóes mundiais de banana para o mercado $j$ e taxa de crescimento percentual do valor das exportaçóes mundiais de banana, entre os períodos 1 e 2 .

\section{ANÁLISE E DISCUSSÁO DOS RESULTADOS}

\subsection{Balança comercial das exportaçóes brasileiras da banana}

Com base nos dados descritos na Tabela 1, verifica-se que a comercialização da banana apresentou saldo positivo na balança comercial agregada desses cinco estados analisados durante o período de 2003 a 2017, mostrando que tal commodity contribui significativamente para a geração de divisas no Brasil. Percebe-se que a banana obteve o maior saldo superavitário no ano de 2010, conquistando o resultado de US\$ 45,37 milhóes, porém a maior taxa média anual de crescimento ocorreu, em 2005, correspondente a $25,38 \%$. Em contrapartida, o ano de 2017 foi o que registrou o menor saldo da balança comercial, de US\$11,45 milhóes, com um decréscimo médio anual de 45,17\%.

Tabela 1 - Valores das exportaçóes, importaçóes e saldo na balança comercial (US\$) da banana dos cinco estados considerados neste estudo, de 2003 a 2017

\begin{tabular}{c|c|c|c|c}
\hline Ano & Exportaçóes & Importaçóes & $\begin{array}{c}\text { Saldo da Balança } \\
\text { Comercial }\end{array}$ & TAC $^{(1)}$ \\
\hline 2003 & $27.662 .528,00$ & 0,00 & $27.662 .528,00$ & - \\
\hline 2004 & $25.467 .521,00$ & 0,00 & $25.467 .521,00$ & $-7,93$ \\
\hline 2005 & $31.931 .211,00$ & 0,00 & $31.931 .211,00$ & 25,38 \\
\hline 2006 & $38.007 .817,00$ & 914,00 & $38.006 .903,00$ & 19,03 \\
\hline 2007 & $43.919 .799,00$ & 0,00 & $43.919 .799,00$ & 15,56 \\
\hline 2008 & $35.090 .108,00$ & 0,00 & $35.090 .108,00$ & $-20,10$ \\
\hline 2009 & $39.253 .334,00$ & 60,00 & $39.253 .274,00$ & 11,86 \\
\hline 2010 & $45.375 .731,00$ & $1.035,00$ & $45.374 .696,00$ & 15,59 \\
\hline 2011 & $39.244 .620,00$ & $13.022,00$ & $39.231 .598,00$ & $-13,54$ \\
\hline 2012 & $35.388 .727,00$ & $16.982,00$ & $35.371 .745,00$ & $-9,84$ \\
\hline 2013 & $35.473 .653,00$ & $33.962,00$ & $35.439 .691,00$ & 0,19 \\
\hline 2014 & $31.691 .700,00$ & $83.849,00$ & $31.607 .851,00$ & $-10,81$ \\
\hline 2015 & $24.912 .290,00$ & $21.403,00$ & $24.890 .887,00$ & $-21,25$ \\
\hline 2016 & $20.900 .450,00$ & $18.824,00$ & $20.881 .626,00$ & $-16,11$ \\
\hline 2017 & $11.494 .580,00$ & $44.371,00$ & $11.450 .209,00$ & $-45,17$ \\
\hline
\end{tabular}

Fonte: elaborado pelos autores com base nos dados do MDIC/Alice Web (2018).

Nota: ${ }^{(1)}$ taxa média anual de crescimento 
Tendo em vista que, em média, 98,57\% do saldo da balança comercial de banana no Brasil são provenientes da comercialização da banana nos estados do Ceará, Paraná, Rio Grande do Norte, Rio Grande do Sul e Santa Catarina nesses últimos 15 anos considerados, torna-se relevante identificar os Estados que mais contribuíram com esse resultado. Os dados exibidos na Tabela 2 revelam que Santa Catarina é o estado que mais contribui com o saldo da balança comercial de banana no Brasil, sendo responsável por mais de $80 \%$ em 2017. Essa participação era de 43,37\% em 2003. Por outro lado, constata-se que o Rio Grande do Norte perdeu uma expressiva participaçáo relativa no saldo da balança comercial de banana no Brasil no período de 2003 a 2017.

Tabela 2 - Participação relativa (\%) dos principais estados brasileiros exportadores de banana no saldo da balança comercial (US\$) dessa commodity, de 2003 a 2017

\begin{tabular}{c|c|c|c|c|c}
\hline Ano & Ceará & Paraná & $\begin{array}{c}\text { Rio Grande do } \\
\text { Norte }\end{array}$ & $\begin{array}{c}\text { Rio Grande do } \\
\text { Sul }\end{array}$ & Santa Catarina \\
\hline 2003 & 0,21 & 0,53 & 53,36 & 2,54 & 43,37 \\
\hline 2004 & 0,15 & 0,31 & 58,16 & 0,17 & 41,21 \\
\hline 2005 & 0,27 & 0,21 & 61,21 & 0,28 & 38,03 \\
\hline 2006 & 10,83 & 0,12 & 64,68 & 0,33 & 24,05 \\
\hline 2007 & 8,91 & 0,06 & 63,97 & 0,48 & 26,57 \\
\hline 2008 & 19,85 & 0,37 & 41,07 & 1,11 & 37,60 \\
\hline 2009 & 21,03 & 0,27 & 35,43 & 1,18 & 42,09 \\
\hline 2010 & 24,68 & 0,09 & 38,89 & 0,52 & 35,82 \\
\hline 2011 & 26,42 & 0,04 & 34,72 & 1,30 & 37,51 \\
\hline 2012 & 27,84 & $-0,03$ & 38,19 & 7,75 & 26,24 \\
\hline 2013 & 32,27 & 0,29 & 30,65 & 12,17 & 24,62 \\
\hline 2014 & 27,50 & 1,34 & 19,93 & 19,32 & 31,91 \\
\hline 2015 & 27,79 & 3,01 & 9,85 & 20,21 & 39,15 \\
\hline 2016 & 29,65 & 1,93 & 11,96 & 4,21 & 52,25 \\
\hline 2017 & 9,91 & $-0,39$ & 4,54 & 4,64 & 81,30 \\
\hline
\end{tabular}

Fonte: elaborado pelos autores com base nos dados do MDIC/Alice Web (2018).

A partir da Tabela 2, também se observa que o único estado que registrou resultado deficitário na comercialização da banana foi o Paraná nos anos de 2012 e 2017. Os estados do Ceará e do Rio Grande do Sul oscilaram suas participaçóes no saldo da balança comercial de banana durante o período analisado.

\section{2 Índice de Vantagem Comparativa Revelada}

Os resultados do Índice de Vantagem Comparativa Revelada de Balassa (IVCR), mostrados na Tabela 3, revelam que, dentre os estados analisados, o Rio Grande do Norte e Santa Catarina se destacaram em termos de competitividade das exportaçóes de banana. 
Em outras palavras, obtiveram resultados acima da unidade em todo o período analisado, indicando, conforme a classificaçáo estabelecida por Hinloopen e Marrewijk (2001), que ambos os Estados, apresentaram forte vantagem comparativa revelada. Essa classificaçáo também é obtida pelo estado do Ceará a partir de 2006, sinalizando que as exportaçóes da fruta contribuem significativamente para a geração de divisas.

Tais resultados obtidos pelo Rio Grande do Norte e pelo Ceará (a partir de 2006) estão relacionados à instalação nesses estados de uma multinacional especializada na produção de banana de alta qualidade, que atende as exigências do mercado europeu (VITTI, 2009). Além desse fator, Andrade, Costa e Maia (2008) também justificam a vantagem comparativa das exportaçóes de banana do Rio Grande do Norte em relaçáo ao país ao fortalecimento do Perímetro Irrigado do Baixo Açu.

Tabela 3 - Índice de Vantagem Comparativa Revelada de Balassa, 2003 a 2017

\begin{tabular}{c|c|c|c|c|c}
\hline Ano & Ceará & Paraná & $\begin{array}{c}\text { Rio Grande do } \\
\text { Norte }\end{array}$ & $\begin{array}{c}\text { Rio Grande do } \\
\text { Sul }\end{array}$ & Santa Catarina \\
\hline 2003 & 0,18 & 0,05 & 115,58 & 0,21 & 7,88 \\
\hline 2004 & 0,16 & 0,03 & 92,43 & 0,02 & 7,73 \\
\hline 2005 & 0,34 & 0,02 & 169,36 & 0,03 & 7,78 \\
\hline 2006 & 15,29 & 0,02 & 236,20 & 0,04 & 5,46 \\
\hline 2007 & 12,36 & 0,01 & 268,04 & 0,05 & 5,73 \\
\hline 2008 & 30,27 & 0,05 & 229,83 & 0,12 & 8,79 \\
\hline 2009 & 29,68 & 0,04 & 209,25 & 0,12 & 9,98 \\
\hline 2010 & 39,24 & 0,01 & 275,62 & 0,07 & 9,53 \\
\hline 2011 & 48,19 & 0,01 & 316,02 & 0,17 & 10,61 \\
\hline 2012 & 53,25 & 0,00 & 354,35 & 1,08 & 7,13 \\
\hline 2013 & 54,78 & 0,05 & 298,10 & 1,17 & 6,84 \\
\hline 2014 & 41,89 & 0,22 & 177,67 & 2,32 & 7,96 \\
\hline 2015 & 50,73 & 0,40 & 59,16 & 2,20 & 9,78 \\
\hline 2016 & 42,12 & 0,24 & 77,27 & 0,47 & 12,65 \\
\hline 2017 & 10,10 & 0,00 & 31,92 & 0,56 & 20,47 \\
\hline Média & 28,57 & 0,08 & 194,05 & 0,57 & 9,22 \\
\hline TAC ${ }^{(1)}$ & 3,32 & 1,53 & 0,00 & 0,63 & 0,10 \\
\hline
\end{tabular}

Fonte: elaborado pelos autores com base nos dados do MDIC/Alice Web (2018).

Nota: ${ }^{(1)}$ taxa média anual de crescimento.

Para Oranje (2003), a banana apresentou desvantagem comparativa revelada em suas exportaçóes brasileiras nas décadas de 1980 e 1990. Esse resultado foi corroborado por Carvalho e Cunha Filho (2007) e por Vitti (2009), para a banana, respectivamente, no período de 1990 a 2003 e entre os anos de 1989 a 2006. Segundo Vitti (2009), esse fato pode ser explicado pelo elevado consumo interno e por não ter qualidade, preço e, ou logística para competir no mercado internacional. 
Ao se considerar a análise desagregada por estados brasileiros, os dados da Tabela 3 apontam que tal resultado se mantém nos estados do Paraná; em quase todo o período investigado para o Rio Grande do Sul, com ressalva para o período de 2012 a 2015; e, no Ceará até 2005 . O resultado obtido por esses dois estados sulistas podem estar associados à ocorrência de "chilling", ou seja, escurecimento da casca da banana devido às baixas temperaturas nos estados do Sul (MATTHIESEN; BOTEON, 2003). Para essas autoras, o bom desempenho catarinense pode ser atribuído à proximidade do mercado, ao grau de tecnificação de produção e pós-colheita e à organização dos produtores.

\section{3 Índice de Vantagem Comparativa Revelada Simétrica}

A fim de analisar a importância das exportaçóes de banana dos principais estados que comercializam a commodity com o mercado externo, pode-se verificar na Tabela 4 os resultados obtidos por meio do Índice de Vantagem Comparativa Revelada Simétrica $\left(\right.$ IVCRS $\left._{i j}\right)$. Conforme se percebe, somente os estados do Rio Grande do Norte e de Santa Catarina apresentaram o $I V C R S_{i j}$ entre $0 \mathrm{e}+1$, revelando que tais Estados possuem vantagem comparativa revelada nas exportaçóes de banana. Cabe destacar que, dentre os dois Estados, apenas Santa Catarina obteve acréscimo durante o período em análise, apesar de a taxa média anual de crescimento ter sido irrisória.

Tabela 4 - Índice de Vantagem Comparativa Revelada Simétrica, 2003 a 2017

\begin{tabular}{c|c|c|c|c|c}
\hline Ano & Ceará & Paraná & $\begin{array}{c}\text { Rio Grande do } \\
\text { Norte }\end{array}$ & $\begin{array}{c}\text { Rio Grande do } \\
\text { Sul }\end{array}$ & Santa Catarina \\
\hline 2003 & $-0,69$ & $-0,90$ & 0,98 & $-0,65$ & 0,77 \\
\hline 2004 & $-0,72$ & $-0,94$ & 0,98 & $-0,97$ & 0,77 \\
\hline 2005 & $-0,50$ & $-0,95$ & 0,99 & $-0,94$ & 0,77 \\
\hline 2006 & 0,88 & $-0,97$ & 0,99 & $-0,93$ & 0,69 \\
\hline 2007 & 0,85 & $-0,99$ & 0,99 & $-0,90$ & 0,70 \\
\hline 2008 & 0,94 & $-0,91$ & 0,99 & $-0,79$ & 0,80 \\
\hline 2009 & 0,93 & $-0,93$ & 0,99 & $-0,79$ & 0,82 \\
\hline 2010 & 0,95 & $-0,97$ & 0,99 & $-0,87$ & 0,81 \\
\hline 2011 & 0,96 & $-0,98$ & 0,99 & $-0,71$ & 0,83 \\
\hline 2012 & 0,96 & $-0,99$ & 0,99 & 0,04 & 0,75 \\
\hline 2013 & 0,96 & $-0,91$ & 0,99 & 0,08 & 0,74 \\
\hline 2014 & 0,95 & $-0,64$ & 0,99 & 0,40 & 0,78 \\
\hline 2015 & 0,96 & $-0,43$ & 0,97 & 0,38 & 0,81 \\
\hline 2016 & 0,95 & $-0,61$ & 0,97 & $-0,36$ & 0,85 \\
\hline 2017 & 0,82 & $-1,00$ & 0,94 & $-0,28$ & 0,91 \\
\hline Média & 0,61 & $-0,87$ & 0,98 & $-0,49$ & 0,79 \\
\hline TAC ${ }^{(1)}$ & $-0,22$ & 0,03 & 0,00 & 0,14 & 0,01 \\
\hline
\end{tabular}

Fonte: elaborado pelos autores com base nos dados do MDIC/Alice Web (2018).

Nota: ${ }^{(1)}$ taxa média anual de crescimento. 
Analisando os demais Estados, verifica-se que o Ceará obteve $I V C R S_{i j}$ entre -1 e 0 apenas para os três primeiros anos da série, sendo que, a partir de 2006, o indicador variou entre 0 e +1 , ou seja, a partir deste ano, o Estado passou a obter competitividade na pauta exportadora da banana. Ademais, vale ressaltar que o Paraná foi o único Estado que registrou desvantagem comparativa revelada, pois o seu $I V C R S_{i j}$ variou entre -1 e 0 . Esses resultados ratificam os obtidos pelo IVCR.

\section{4 Índice de Vantagem Comparativa Revelada de Vollrath}

Os resultados do Índice de Vantagem Comparativa Revelada de Vollrath (RCAV) das exportaçóes de banana dos principais estados exportadores, no período de 2003 a 2017, estão descritos na Tabela 5. Esse indicador aponta que o Rio Grande do Norte e Santa Catarina apresentaram $R C A V$ acima da unidade em toda a série estudada, significando que tais Estados possuem vantagem comparativa na exportação da commodity investigada. Tais resultados são coerentes com os resultados dos indicadores anteriormente estudados, mostrando que, de todos os Estados, o Rio Grande do Norte e Santa Catarina foram os que obtiveram competitividade na pauta exportadora de banana no período analisado. Além disso, observa-se na Tabela 5 que apesar de o Rio Grande do Norte ter obtido elevadíssimo $R C A V$ quando comparado com os demais Estados, a sua taxa média anual de crescimento foi a menor, ou mais especificamente, ficou nula.

Tabela 5 - Índice de Vantagem Comparativa Revelada de Vollrath

\begin{tabular}{c|c|c|c|c|c}
\hline Ano & Ceará & Paraná & $\begin{array}{c}\text { Rio Grande do } \\
\text { Norte }\end{array}$ & $\begin{array}{c}\text { Rio Grande do } \\
\text { Sul }\end{array}$ & Santa Catarina \\
\hline 2003 & 0,18 & 0,05 & 237,02 & 0,19 & 12,48 \\
\hline 2004 & 0,16 & 0,03 & 208,90 & 0,01 & 12,03 \\
\hline 2005 & 0,33 & 0,02 & 433,19 & 0,03 & 11,74 \\
\hline 2006 & 17,07 & 0,01 & 695,94 & 0,03 & 6,86 \\
\hline 2007 & 13,51 & 0,01 & 789,38 & 0,05 & 7,43 \\
\hline 2008 & 37,58 & 0,04 & 401,62 & 0,11 & 13,39 \\
\hline 2009 & 37,57 & 0,03 & 341,20 & 0,11 & 16,51 \\
\hline 2010 & 52,21 & 0,01 & 479,89 & 0,06 & 14,32 \\
\hline 2011 & 65,61 & 0,01 & 508,03 & 0,16 & 16,39 \\
\hline 2012 & 73,94 & 0,00 & 603,55 & 1,09 & 9,32 \\
\hline 2013 & 80,90 & 0,05 & 448,29 & 1,19 & 8,74 \\
\hline 2014 & 57,64 & 0,21 & 227,06 & 2,63 & 11,21 \\
\hline 2015 & 70,30 & 0,38 & 66,01 & 2,51 & 15,43 \\
\hline 2016 & 59,55 & 0,23 & 88,32 & 0,44 & 25,24 \\
\hline 2017 & 11,09 & 0,00 & 33,42 & 0,54 & 98,46 \\
\hline Media & 38,51 & 0,07 & 370,79 & 0,61 & 18,64 \\
\hline TAC ${ }^{(1)}$ & 3,74 & 1,53 & 0,00 & 0,68 & 0,31 \\
\hline
\end{tabular}

Fonte: elaborado pelos autores com base nos dados do MDIC/Alice Web (2018).

Nota: ${ }^{(1)}$ taxa média anual de crescimento. 
O $R C A V$ para o estado do Paraná mostrou que durante todo o período estudado obteve desvantagem comparativa, significando que o indicador ficou abaixo da unidade. Em relação ao estado do Ceará, verifica-se que apresentou desvantagem comparativa nos três primeiros anos da série, náo se verificando para o restante do período, onde obteve competitividade nas exportaçôes dessa fruta. Esses resultados para o Ceará estão de acordo com os obtidos por Soares, Sousa e Barbosa (2013) para a banana. Enquanto que o Rio Grande do Sul, em praticamente toda a série analisada, apresentou desvantagem comparativa, excetuando o período de 2012 a 2015, na qual o indicador ficou acima da unidade.

\subsection{Modelo Constant Market Share}

Com base nos resultados descritos na Tabela 6, o Brasil, entre 2003 e 2007, período I, foi responsável por $0,6 \%$ das exportaçôes mundiais de banana, participação que foi decrescente, no período II (2008-2012), sendo responsável por 0,5\% das exportaçóes mundiais e, no período III (2013-2017), por apenas 0,2\% das exportaçóes, ou seja, durante o período investigado, o País diminuiu sua participação no mercado mundial de banana.

Tabela 6 - Valor médio das exportaçóes mundiais e brasileiras de banana, em US\$ FOB, e participação do Brasil nas exportaçôes mundiais de banana, período de 2003 a 2017

\begin{tabular}{c|c|c|c}
\hline & $2003 / 2007$ & $2008 / 2012$ & $2013 / 2017$ \\
\hline Exportações Mundiais & $5.782 .941 .296,20$ & $8.277 .240 .680,40$ & $10.054 .179 .451,60$ \\
\hline Exportaçóes Brasileiras & $34.604 .451,80$ & $38.953 .569,20$ & $24.982 .952,40$ \\
\hline Market Share (\%) & 0,6 & 0,5 & 0,2 \\
\hline
\end{tabular}

Fonte: elaborada pelos autores com base nos dados do MDIC / Alice Web (2018) e do Un Comtrade (2018).

A análise das exportações de banana indica que, no período de 2003 a 2017, os maiores importadores da commodity brasileira foram Argentina, Uruguai, Países Baixos (Holanda) e Polônia, sendo que os dois primeiros países em conjunto foram responsáveis por aproximadamente $42,17 \%$ das importaçóes do produto brasileiro.

Conforme consta na Tabela 7, a decomposição das fontes de crescimento das exportações brasileiras de banana, do período II em relação ao período I, indica que apenas os efeitos do crescimento do comércio mundial e destino das exportaçóes foram positivos, destacando-se, principalmente, o destino das exportaçóes, pois apontou que as exportaçóes de banana foram direcionadas para os países (Argentina, Uruguai, Holanda e Polônia), que apresentaram taxas de crescimento por tal commodity superiores as dos demais países no âmbito mundial. No que concerne ao efeito competitividade apresentou resultado negativo, mostrando que o Brasil náo registrou competitividade nas exportaçóes de banana, pois náo conseguiu igualar-se aos padróes de eficiência vigentes no resto do mundo quanto à utilização de recursos e à qualidade do bem transacionado. 
Tabela 7 - Fontes de crescimento das exportaçóes brasileiras de banana, no período de 2003 a 2017

\begin{tabular}{c|c|c}
\hline $\begin{array}{c}\text { Fontes de crescimento das } \\
\text { exportaçóes brasileiras de banana }\end{array}$ & $\begin{array}{c}2003 / 2007 \text { a 2008/2012 } \\
(\%)\end{array}$ & $\begin{array}{c}2008 / 2012 \text { a 2013/2017 } \\
(\%)\end{array}$ \\
\hline Crescimento do Comércio Mundial & 42,56 & $-14.553,07$ \\
\hline Destino das Exportaçóes & 543,70 & $14.451,29$ \\
\hline Competitividade & $-486,25$ & 201,79 \\
\hline
\end{tabular}

Fonte: elaborada pelos autores com base nos dados do MDIC / Alice Web (2018) e do Un Comtrade (2018).

Analisando a decomposição das fontes de crescimento da banana, observa-se que, no período III em relação ao período II, o efeito crescimento do comércio mundial registrou resultado negativo, indicando que as exportaçóes brasileiras para o último período decresceram fortemente. Contudo, verificando-se os demais efeitos, constatou-se que a competitividade apresentou resultado positivo, de 201,79\%, ou seja, as exportaçóes do produto em análise conquistaram parcela de crescimento dos ganhos decorrentes de participação das exportaçóes de banana nos diferentes mercado devido aos ganhos de competitividade. O efeito competitividade também foi preponderante nos estudos de Sousa Neto, Moura e Cabral (2006) e Vitti (2009) para a banana.

Ademais, vale destacar que o efeito destino das exportaçóes foi o que se destacou novamente, pois apontou que o Brasil está direcionando suas exportaçóes da commodity investigada para mercados mais dinâmicos que a média do comércio internacional.

\section{CONSIDERAÇÓES FINAIS}

Este estudo objetivou analisar a competitividade das exportaçóes de banana proveniente dos estados do Ceará, Paraná, Rio Grande do Norte, Rio Grande do Sul e Santa Catarina no período de 2003 a 2017 por meio dos indicadores de competitividade, bem como identificar as fontes de crescimento das exportações brasileiras de banana.

Os resultados dos indicadores de desempenho $I V C R_{i}, I V C R S_{i j}$ e $R C A V$ mostram que, dos cinco Estados analisados (Ceará, Paraná, Rio Grande do Norte, Rio Grande do Sul e Santa Catarina), apenas o Rio Grande do Norte e Santa Catarina registraram vantagem comparativa nas exportações de banana em toda a série analisada. Vale ressaltar que a competitividade da pauta exportadora de banana foi mais expressiva para o Rio Grande do Norte, significando que tal produto constitui uma fonte importante na geração de divisas para o Estado.

Por sua vez, o Ceará obteve competitividade nas exportações da commodity em análise a partir do ano de 2006 para os três indicadores empregados. Contudo, ao verificar as exportaçóes de banana para o Rio Grande do Sul, constatou-se que, dentre o período analisado, apenas obteve competitividade no período entre 2012 e 2015 . Ademais, cabe destacar que o Paraná foi o único Estado que obteve desvantagem comparativa em toda a série investigada, com base nos três índices utilizados na presente pesquisa. 
Quanto aos resultados do modelo Constant Market Share, observou-se que o efeito destino das exportaçóes foi o principal fator determinante nas exportaçóes brasileiras de banana. Contudo, ao analisar o efeito crescimento do comércio mundial, seu resultado foi positivo quando se compara o período II com o período I, enquanto que, no período III em relaçâo ao II, obteve resultado negativo, evidenciando que as exportaçóes da commodity decresceram no último subperíodo analisado (2013-2017). Ademais, é importante destacar que o efeito competitividade não foi determinante nas exportaçóes do produto em análise entre os subperíodos II em relação I, mas foi expressivo para as exportações de banana dos subperíodos III com II, estando de acordo com a literatura.

\section{REFERÊNCIAS}

ANDRADE, M. E.; COSTA, G. C.; MAIA, A. C. N. Dinâmica e competitividade das exportaçôes de frutas do Rio Grande do Norte no período de 1999 a 2005. In: Congresso da Sociedade Brasileira de Economia, Administração e Sociologia Rural, 46, 2008.

Anais... Rio Branco, AC: SOBER, 2008.

ANDREKOWISK, F. F. F. Um estudo sobre a teoria do comércio internacional de Linder. 67 p. Dissertação (Economia). Universidade de Brasília, Brasília, 2010.

BALASSA, B. Trade Liberalization and "Revealed" Comparative Advantage.

Manchester School of Economic and Social Studies, Oxford, v. 33, p. 99-123, 1965.

BARBOSA, W. F.; SOUSA, E. P.; CORONEL, D. A.; AMORIM, A. L. Desempenho exportador do setor de carnes em Santa Catarina. Textos de Economia. Florianópolis, v.14, n.2, p.70-93, 2011.

BENDER, S.; LI, K. W. The changing trade and revealed comparative advantages of Asian and Latin American manufacture exports. New Haven: Yale University, Economic Growth Center, 2002. 26 p.

CARDOSO, A. S. Vantagens comparativas das exportaçóes brasileiras para a Alemanha: o modelo de Heckscher-Ohlin. 54 p. Dissertação (Economia de Empresas). Universidade Católica de Brasília, Brasília, 2003.

CARMO, E. C.; MARIANO, J. Economia Internacional. 6 ed. São Paulo: Saraiva, 2010.

CARVALHO, F. M. A. Método "Constant Market Share". In. SANTOS, M. L.; VIEIRA, W. C. (Ed.). Métodos Quantitativos em Economia. Viçosa, UFV, p. 225 - 242, 2004.

CARVALHO, F. M. A. O comportamento das exportaçóes brasileiras e a dinâmica do complexo agroindustrial. 1995. Tese (Economia Aplicada) - Escola Superior de Agricultura "Luiz de Queiroz", Universidade de São Paulo, São Paulo, 1995. 
CARVALHO, R. M.; CUNHA FILHO, M. H. Competitividade da fruticultura brasileira no mercado internacional. Revista de Economia e Agronegócio, Viçosa, v. 5, n. 4, p. 547-566, 2007.

CASSANO, F. A. A teoria econômica e o comércio internacional. Pesquisa \& Debate. São Paulo, v. 13, n. 1(21), p. 112-128, 2002.

CEPEA - CENTRO DE ESTUDOS AVANÇADOS EM ECONOMIA APLICADA. Banana/CEPEA: exportações recuam 61\% em 2017. 2017. Disponível em: <https:// www.cepea.esalq.usp.br/br/diarias-de-mercado/banana-cepea-exportacoes-recuam-61em-2017.aspx>. Acesso em: 15/03/2018.

CORONEL, D. A.; SOUSA, E. P.; AMORIM, A. L. Desempenho exportador do mel natural nos estados brasileiros. Pesquisa \& Debate, São Paulo, v. 22, n. 2 (40), p. 343360, 2011.

FIORAVANÇO, J. C. Mercado mundial da banana: produção, comércio e participação brasileira. Informaçóes Econômicas. São Paulo, v. 33, n. 10, p. 15-27, 2003.

GOULART JÚNIOR, R. Banana. In: SANTOS, A. A. et al. (Orgs.). Síntese Anual da Agricultura em Santa Catarina. Florianópolis: EPAGRI/CEPA, p. 40-48, 2017.

HINLOOPEN, J.; MARREWIJK, C. V. On the empirical distribution of the Balassa Index. Weltwirtschaftliches Archiv, v. 137, n. 1, p. 1-35, 2001.

KIM, T. S. The revealed competitiveness of major ports in the East Asian Region: an additive Market Share Analysis. The Asian Journal of Shipping and Logistics, v. 31, n. 4, p. 429-435, 2015.

LAURSEN, K. Revealed comparative advantage and the alternatives as measures of International specialization. Eurasian Business Review, v. 5, n. 1, p. 99-115, 2015.

LAZARETTI, L. R.; PRESOTTO, E.; TEIXEIRA, F. O.; FEISTEL, P. R.

Competitividade e intercâmbio comercial do Rio Grande do Sul: uma análise da cadeia produtiva da carne de frango, no período de 1987-2013. In: Congresso da Sociedade Brasileira de Economia, Administração e Sociologia Rural, 55, 2017. Anais... Santa Maria, RS: SOBER, 2017.

LIMA, M. G.; LÉLIS, M. T. C.; CUNHA, A. M. Comércio Internacional e Competitividade do Brasil: um estudo comparativo utilizando a metodologia ConstantMarket-Share para o período 2000-2011. Revista Economia e Sociedade, Campinas, v. 24, n. 2, p. 419-448, ago. 2015. 
MATTHIESEN, M. L.; BOTEON, M. Análise dos principais polos produtores de banana no Brasil. In: Congresso da Sociedade Brasileira de Economia, Administração e Sociologia Rural, 41, 2003. Anais... Juiz de Fora, MG: SOBER, 2003.

\section{MDIC - MINISTÉRIO DO DESENVOLVIMENTO, INDÚSTRIA E COMÉRCIO} EXTERIOR. Sistema Aliceweb. Disponível em: <http://aliceweb.mdic.gov.br/>. Acesso em: 15/03/2018.

MENDONÇA, T. G.; LÍRIO, V. S.; GOMES, M. F. M.; CAMPOS, A. C. Inserção do Brasil no mercado mundial de castanha de caju no período de 1990 a 2005 . Revista Econômica do Nordeste, v. 40, p. 133-152, 2009.

OLIVEIRA, A. C. Competitividade e parcela de mercado: uma abordagem ConstantMarket-Share para a soja em grão brasileira (2000-2011). Monografia (Bacharel em Ciências Econômicas) - Universidade Federal de Alfenas, Minas Gerais, 2014.

OLIVEIRA, I. T. M. Livre Comércio versus protecionismo: uma análise das principais teorias do comércio internacional. Revista Urutágua. Maringá, Paraná, n. 11, p. 1-18, 2007.

OLIVEIRA, M. F.; SCHLINDWEIN, M. M. Índice de Vantagem Comparativa Revelada para o complexo soja da região Centro-Oeste brasileira. Revista de Estudos Sociais. Cuiabá, MT, v. 17, n. 33, p. 109-131, 2015.

OLIVEIRA, V. P. S.; ROSA, T. D. L. F. Comércio exterior paranaense por setores de contas nacionais, no período de 2007 a 2011: uma aplicação de indicadores de comércio internacional. In: Encontro de Produção Científica e Tecnológica, 8, 2013. Anais... Campo Mourão, PR: EPCT, 2013.

ORANJE, M. Competitividade das frutas brasileiras no comércio internacional. 114 p. Tese (Economia Aplicada) - Universidade Federal de Viçosa, Minas Gerais, 2003.

PIMENTEL, R. V. Uma análise da competitividade da bananicultura em Santa Catarina. 54 p. Monografia (Ciências Econômicas). Universidade Federal de Santa Catarina, Florianópolis, 2006.

RICARDO, D. Princípios de Economia Política e Tributação. São Paulo: Nova Cultura, 1996.

SANTOS, J. L. S.; SOUSA, E. P. Competitividade das Exportações Brasileiras de Melão. Revista de Política Agrícola. Brasília, v. 26, n. 3, p. 31-43, 2017.

SANTOS, J. L. S.; SOUSA, E. P.; SOARES, N. S. Competitividade das exportaçóes dos principais produtos do agronegócio no Nordeste brasileiro. In: Congresso da Sociedade 
Brasileira de Economia, Administração e Sociologia Rural, 55, 2017. Anais... Santa Maria, RS: SOBER, 2017.

SANTOS, J. R. P.; SANTOS, J. M. Estudo da competitividade das exportações de melão nos estados de Rio Grande do Norte e Ceará (1997-2014). Revista de Desenvolvimento Econômico. Salvador, BA, v. 2, n. 34, p. 616-642, 2016.

SEBRAE - Serviço Brasileiro de Apoio às Micro e Pequenas Empresas. Banana. Estudos de Mercado SEBRAE/ESPM. Setembro, 2008.

SEBRAE - Serviço Brasileiro de Apoio às Micro e Pequenas Empresas. Mercado de Fruticultura - panorama do setor no Brasil. Boletim de Inteligência, Outubro, 2015.

SILVA, T. J. J.; FERREIRA, M. O.; LIMA, J. R. F. Competitividade das exportaçóes de manga e uva do Vale Submédio do São Francisco. Revista de Política Agrícola. Brasília, v. 25, n. 4, p. 152-154, 2016.

SILVA, J. L. M.; MARTINS, J. S. Competitividade e parcela de mercado: uma análise do Constant Market Share para o mercado de camarão brasileiro. Revista Econômica do Nordeste. Fortaleza, v. 43, n. 1, p. 125-137, 2012.

SIQUEIRA, K. B.; PINHA, L. C. Vantagens Comparativas Reveladas do Brasil no comércio internacional de lácteos. Boletim de Pesquisa e Desenvolvimento. Embrapa Gado, 2011.

SOARES, N. S.; SOUSA, E. P.; BARBOSA, W. F. Desempenho exportador do agronegócio no Ceará. Revista de Política Agrícola. Brasília, v. 22, n. 2, p. 54-66, 2013.

SOUZA NETO, J.; MOURA, M. Q.; CABRAL, J. E. O. Exportaçóes brasileiras de banana: um estudo de competitividade no mercado internacional. In: Congresso da Sociedade Brasileira de Economia, Administração e Sociologia Rural, 44, 2006. Anais... Fortaleza, CE: SOBER, 2006.

VITTI, A. Análise da competitividade das exportaçóes brasileiras de frutas selecionadas no mercado internacional. 105 p. Dissertação (Economia Aplicada) Escola Superior de Agricultura "Luiz de Queiroz", Universidade de São Paulo, São Paulo, 2009.

WORLD INTEGRATED TRADE SOLUTION - WITS. UN Comtrade Database.

Disponível em: <http://wits.worldbank.org/>. Acesso em: 13/08/2018. 